\title{
Vínculos dos Indivíduos com a Organização: Análise da Produção Científica Brasileira 2000-2010
}

\author{
Antonio Virgílio Bittencourt Bastos ${ }^{1}$ \\ Letícia Gomes Maia \\ Universidade Federal da Bahia \\ Ana Carolina de Aguiar Rodrigues \\ Universidade de São Paulo \\ Magno Oliveira Macambira \\ Universidade Federal da Bahia \\ Jairo Eduardo Borges-Andrade \\ Universidade de Brasilia
}

\begin{abstract}
RESUMO - Este estudo procurou analisar a produção científica brasileira 2000-2010 sobre vínculos do empregado com a organização, abrangendo quatro temas principais: comprometimento organizacional, contratos psicológicos, cidadania organizacional e percepções de apoio e de justiça e equidade. Justifica essa escolha a importância dessas questões para o campo de pesquisa micro-organizacional e a intensa concentração de pesquisa sobre o tema. Sessenta e três artigos foram identificados. As análises seguiram três ênfases: aspectos metodológicos; conteúdos dos artigos, suas contribuições e limitações; e as redes de parcerias entre autores e instituições. Os resultados indicam altos níveis de nebulosidade conceitual e de sobreposição de instrumentos, e pouca interação entre grupos de pesquisa. Com base nos resultados, foi proposta uma agenda de pesquisa.
\end{abstract}

Palavras-chave: comprometimento, cidadania, contrato psicológico, suporte, justiça e equidade

\section{Employee-Organization Linkages: Analysis of Brazilian Scientific Production 2000-2010}

\begin{abstract}
This study sought to analyze the Brazilian scientific production in 2000-2010 on employee's linkages with the organization, covering four main topics: organizational commitment, psychological contracts, organizational citizenship and perceptions of support, justice and equity. The importance of these issues to micro-organizational research and the intense research on the topic are the reasons for making this choice. Sixty-three articles were identified. The analyses followed three emphases: methodological features; content of articles, their contributions and limitations; and partnership networks between authors and institutions. The results show high levels of conceptual haziness and overlapping of instruments, and little interaction between research groups. Based on the findings, a research agenda is proposed.
\end{abstract}

Keywords: commitment, citizenship, psychological contract, support, justice and equity

O entendimento da gênese e da dinâmica dos vínculos existentes entre indivíduos e organizações tem clara repercussão sobre os processos referentes à gestão. Incide na formulação de políticas e no desenvolvimento de práticas e modelos mais específicos de como lidar com as pessoas, seus trabalhos, suas relações no interior das equipes, suas relações com os líderes e gestores. O estudo dessa questão básica tem o poder de articular aspectos teóricos e tecnológicos importantes para o desempenho das funções sociais esperadas das organizações. Por essas razões, a investigação desses vínculos assumiu centralidade no campo micro da disciplina de Comportamento Organizacional, em uma tradição que remonta aos anos de 1960 e antecede até mesmo a formalização da mencionada disciplina.

Os objetivos deste trabalho consistem em analisar e caracterizar, quantitativa e qualitativamente, a produção

1 Endereço para correspondência: Rua Macapá, 461/601, Ondina, Salvador, BA, Brasil. CEP: 40.170-150.E-mail: antoniovirgiliobastos@ gmail.com científica brasileira sobre os vínculos entre indivíduos e organizações; descrever as redes de pesquisadores responsáveis por essa produção na primeira década do século XXI; identificar tendências e lacunas fundamentais para a construção ou redirecionamento da agenda de pesquisa que mobiliza essa comunidade científica. Espera-se contribuir para aprofundar a discussão sobre os dilemas teóricos, conceituais e metodológicos que cercam o estudo dos vínculos do trabalhador com a sua organização empregadora e direcionar os esforços dos pesquisadores para que o conhecimento sobre esses vínculos avance.

Diante do amplo e diversificado conjunto de vínculos do trabalhador, quatro construtos se destacam por se reportarem de forma mais direta ao vínculo que o indivíduo estabelece com a organização. São eles: comprometimento, contratos psicológicos, cidadania organizacional e percepções de suporte e de justiça e equidade. Os demais construtos integram dimensões de um desses citados (como é o caso da identificação com a organização) ou se associam a aspectos ou dimensões da vida organizacional mais específicos (como 
é o caso de motivação, mais voltada para o trabalho, ou o caso de clima, como um conglomerado de percepções de aspectos singulares).

\section{A produção científica e suas bases teóricas}

Os quatro construtos escolhidos como foco da presente revisão contam com uma produção científica respeitável. Em levantamento nas bases de dados de Ciências Humanas e Ciências Sociais Aplicadas, disponíveis no Portal de Periódicos ${ }^{1}$ da Coordenação de Aperfeiçoamento de Pessoal de Nível Superior, foi possível identificar para cada construto, o quantitativo de artigos que utilizavam palavras-chave correspondentes em seus títulos. Os dados constantes da Figura 1 indicam a importância crescente atribuída pela comunidade científica a esses temas. Por serem bases que publicam adicionalmente aos estudos brasileiros um conjunto expressivo de trabalhos internacionais, esse levantamento permitiu também compreender as tendências gerais de pesquisa para cada um desses construtos.

Comprometimento no trabalho é, certamente, o construto mais intensamente investigado e cujo interesse de pesquisa surge mesmo antes dos anos 1980.
Nessa década, o interesse pelo conceito ganha maior destaque, a sua produção duplica nos anos 1990 e esse crescimento é ainda mais expressivo a partir do ano 2000. Foram identificados 2.388 itens publicados, dos quais $71,9 \%$ publicados a partir de 2000. Estamos diante de um dos temas atualmente mais investigadosno campo microorganizacional. $\mathrm{O}$ interesse pelo construto de contrato psicológico é mais recente ainda. Os primeiros artigos que tomam contrato psicológico como tema principal, surgem no início dos anos 1990 e a produção se mantém ainda muito reduzida por toda essa década. Essa produção mais do que duplica nos anos 2000, embora esse seja, dentre os quatro, o construto menos intensamente investigado (206 artigos). O construto cidadania organizacional surge timidamente no final dos anos 1980 e tem uma produção ainda bem incipiente na primeira metade da década de 1990. Depois, experimenta um consistente crescimento, especialmente nos últimos cinco anos. Foram identificados 533 artigos sobre cidadania organizacional, dos quais $88,9 \%$ também publicados a partir do ano 2000. Finalmente, o construto percepção do suporte organizacional é mais antigo, com artigos identificados antes mesmo dos anos 1980. A produção científica, no entanto, mantém-se bastante reduzida até o fim dos anos 1990. Cresceu exponencialmente na primeira década dos anos 2000,

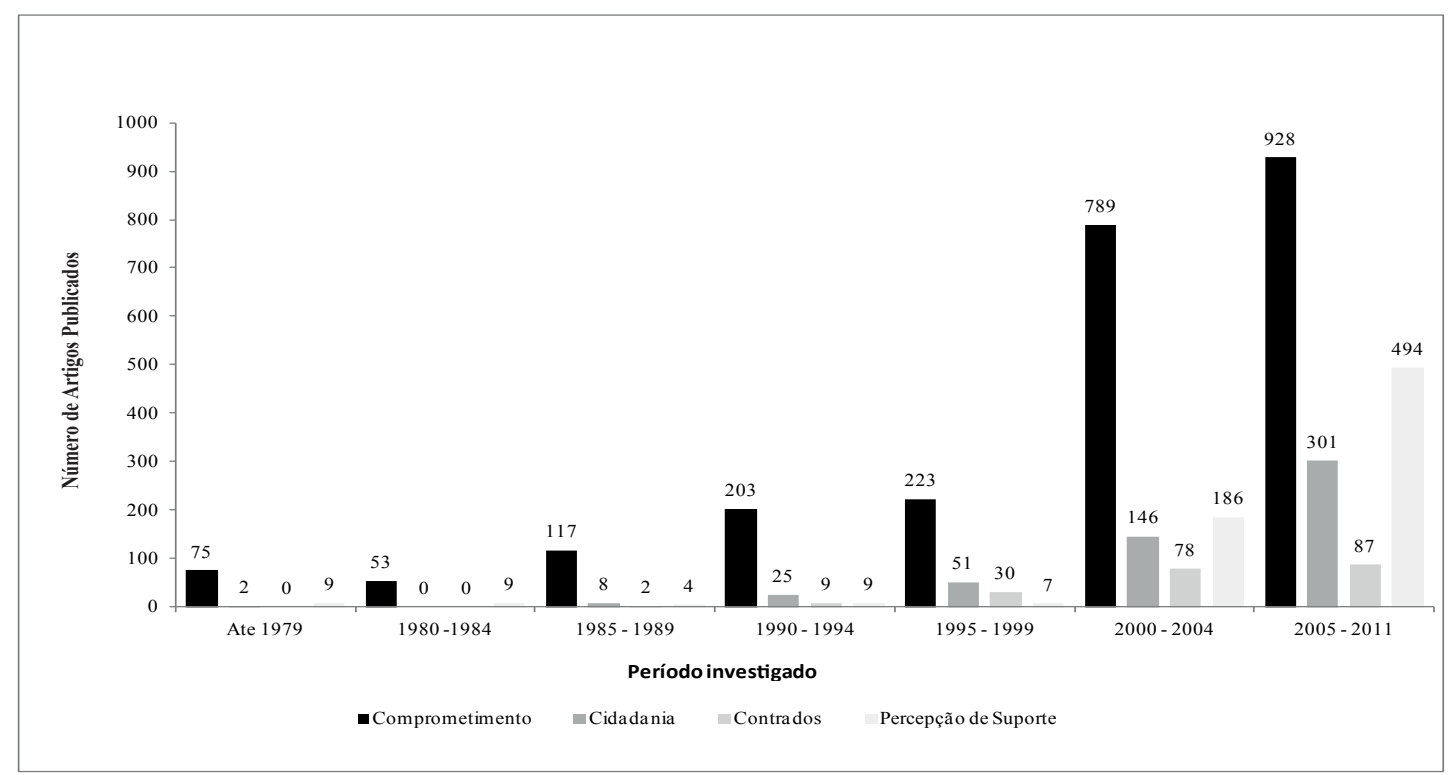

Figura 1. Frequência da produção científica em periódicos disponíveis no Portal de Periódicos (CAPES, 2011).

1 Trata-se de uma biblioteca virtual, financiada pelo governo brasileiro, que organiza e disponibiliza a instituições de ensino e pesquisa do Brasil um abrangente acervo de títulos, bases, livros, enciclopédias e obras de referência da produção científica do Brasil e de outros países. As bases consultadas foram: ASP (EBSCO), Cambridge Journals Online, Education Full Text (Wilson), Emerald Fulltext (Emerald), JSTOR, OECD iLibrary, Oxford Journals (Oxford University Press), Project Muse, PsycArticles (APA), SAGE Journals Online, ScienceDirect (Elsevier), SocINDEX (EBSCO), SpringerLink (MetaPress), Wiley Online Library. O levantamento em questão foi realizado em 2011. Foram inseridas no sistema, em etapas independentes, as palavraschave de cada um dos quatro construtos investigados. A partir desse procedimento, o portal oferece a lista dos estudos publicados para cada palavra-chave, em todas as bases, distribuídos por período. período em que se encontram 94,7\% dos artigos. Os dados quantitativos e as informações sobre os periódicos que mais publicaram trabalhos sobre os quatro construtos revelam o crescente interesse na comunidade de pesquisa por estudar temas cuja investigação está consolidada. Pode ser um sinal de que a complexidade desses fenômenos está distante de esgotar novas questões de investigação. As publicações aconteceram em muitos periódicos indexados. Aqueles em que a produção é mais concentrada são reconhecidamente importantes periódicos, com fatores de impacto relevantes. Assim, estudar os vínculos do indivíduo com a organização continua sendo, mais do que antes, um importante tópico no campo do Comportamento Organizacional. Teria ocorrido um expressivo crescimento equivalente, nos últimos anos, 
da contribuição brasileira nesse domínio de pesquisa? A seguir, para cada um dos construtos, será apresentada uma breve análise do estado atual da produção científica e dos desafios conceituais, teóricos e metodológicos que cercam a sua investigação.

Na pesquisa sobre comprometimento no trabalho, percebe-se uma tendência a tratá-lo como fonte e receptáculo de diversos tipos de vínculo. Isso gerou dilatação do construto, imprecisão dos estudos e ameaça à validade dos resultados encontrados (Bastos, 1994; Brown, 1996; Morrow, 1983; Osigweh, 1989). Não há um consenso em relação à origem dos estudos sobre o comprometimento, assim como não há acordo para os diferentes enfoques que lhe têm sido atribuídos.

A primeira tentativa de compilar os estudos sobre comprometimento com foco na organização foi feita por Mowday, Porter e Steers (1982), com o objetivo de propor um modelo que abarcasse os desenvolvimentos teóricos já realizados. Assim, esses autores definiram o construto como uma força relativa à identificação e ao envolvimento do indivíduo com a organização, caracterizada pela aceitação dos objetivos e valores organizacionais, desejo de manterse como membro e de exercer esforço em benefício da organização. Por muitos anos, esse significado e a escala construída pelos autores foram amplamente utilizados, em uma perspectiva atitudinal-afetiva. Posteriormente, Meyer e Allen (1991) conceberam um novo modelo, emergente de diversos estudos. Esse modelo era composto por três dimensões que organizavam as diferentes naturezas do comprometimento organizacional: a base de continuação, que traduz uma racionalidade instrumental, incluindo cálculos dos custos envolvidos quando da descontinuidade de uma linha de ação; a base afetiva, pautada principalmente na identificação e no afeto para com a organização; e a base normativa, cuja natureza é resultado dos valores e normas organizacionais internalizadas pelos trabalhadores.

O mérito dessa sistematização do conceito é reconhecido e o modelo tridimensional tornou-se referência para muitas pesquisas. Contudo, problemas conceituais e empíricos levantam discussões sobre sua pertinência: a sobreposição das bases afetiva e normativa, a inadequação das propriedades psicométricas das escalas e as inconsistências empíricas da base de continuação, que apresenta relações positivas com variáveis indesejáveis e negativas com variáveis desejáveis (Cooper-Hakim \& Viswesvaran, 2005; Meyer, Stanley, Herscovitch, \& Topolnytsky, 2002; Rodrigues \& Bastos, 2010).

Os primeiros usos do termo contrato psicológico ocorreram a partir de 1958 (Argyris, 1960; Levinson, Price, Munden, \& Solley, 1962; Menninger, 1958; Schein, 1965). Contudo, o construto somente veio a receber mais atenção dos pesquisadores a partir da reformulação de Rousseau (1989). Esta autora argumentou que os contratos psicológicos são formados a partir de percepções individuais dos comportamentos observáveis, e não a partir de necessidades humanas básicas ou expectativas inconscientes, como os precursores supracitados estabeleciam. Esse redirecionamento viabilizou a quantificação e a realização de investigações por meio de métodos quantitativos e, por isto, talvez a maioria dos estudos utilize tais métodos. Os estudos longitudinais têm um número reduzido de publicações. O mesmo pode ser afirmado a respeito dos estudos sobre os antecedentes e consequentes do contrato psicológico. As pesquisas atendem essencialmente a dois principais temas: o conteúdo e a quebra do contrato psicológico. O volume de pesquisas desde essa reformulação é considerável, mas o conceito ainda carece de desenvolvimento teórico que lhe conceda certa maturidade. São muitas as questões por responder.

Os estudos sobre cidadania organizacional foram impulsionados a partir da sua definição como comportamentos individuais discricionários, "que não fazem parte dos requisitos do papel ou da função" (Organ, 1988, p. 4), que não são recompensados direta ou explicitamente e que promovem a eficácia da organização. Apesar de ser a definição mais amplamente adotada, a discricionariedade e a não recompensa foram objeto de críticas por diversos pesquisadores, devido à dificuldade para se distinguir comportamentos de papel e extra-papel, entre outros aspectos. O constructo constitui um objeto tradicional de pesquisas, mas ainda carece de uma definição consistente, consensual e delimitada.

Os primeiros estudos acerca de percepção de justiça e equidade no trabalho surgiram durante a década de 1960. Rhoades e Eisenberger (2002) identificaram que indivíduos em situações injustas, desenvolviam estratégias mentais ou comportamentais para modificar tal situação. A percepção de justiça e equidade foi o mais forte fator antecedente de percepção de suporte organizacional. Esse é um importante fenômeno psicossocial no ambiente organizacional, baseado na norma da reciprocidade (Gouldner, 1960), que indica o grau em que os empregados acreditam que sua organização valoriza suas contribuições e se preocupa com seu bem-estar (Eisenberger, Huntington, Huntington, \& Sowa, 1986).

O domínio de estudo sobre os vínculos do indivíduo com a organização, apesar do seu expressivo crescimento atual, ainda apresenta desafios para os pesquisadores. Demanda investimento em uma agenda de investigação que busque reduzir a confusão conceitual, os problemas de mensuração e a construção de modelos teóricos mais gerais e abrangentes que possam ampliar os impactos no mundo organizacional da pesquisa realizada. Como a investigação brasileira, em Comportamento Organizacional, contribuiu para isso? Baseada em que redes de pesquisadores? Buscar respostas para tais questões é o objetivo central do presente trabalho.

\section{Método}

Com a finalidade de identificar artigos relacionados ao estudo de vínculos entre indivíduos e organização, foram revisados 14 periódicos brasileiros entre 2000 e 2010: cinco de administração (Revista de Administração da USP - RAUSP, Revista de Administração de Empresas - RAE, Revista de Administração Pública - RAP, Organizações e Sociedade - O\&S, Revista de Administração Contemporânea - RAC) e nove de psicologia (Psicologia: Teoria e Pesquisa, Psicologia em Estudo, Psicologia. Ciência e Profissão, Psicologia, Reflexão e Crítica, Estudos de Psicologia de Campinas, Estudos de Psicologia, de Natal, Psicologia, Organizações e Trabalho - rPOT, PSICO da Universidade São 
Francisco, PSICO da Pontifícia Universidade Católica do Rio Grande do Sul). A escolha desses periódicos fundamentouse em critérios de indexação do veículo e conceituação avaliativa em âmbito nacional pela Capes. Em suas principais áreas de concentração, no ano de 2012, dois desses periódicos obtiveram classificação igual a B1, e os demais obtiveram classificação igual ou superior a A2.

Para análise dos 63 trabalhos selecionados, foi criado um procedimento padronizado para extração e classificação de informações relevantes. As principais categorias foram: natureza e finalidade do estudo, delineamento da investigação, natureza da amostragem, origem dos dados coletados, procedimentos de coleta e análise dos dados, setor e segmento da economia.

A revisão dos periódicos, a identificação e o registro dos artigos foram realizados por meio de uma parceria entre alunos e professores das Universidades de Brasília, Salgado de Oliveira (Campus de Niterói, RJ) e Federal da Bahia. Descrições mais detalhadas dos periódicos investigados e dos critérios de categorização dos artigos estão apresentadas nas Tabelas 3 e 6 do trabalho publicado por Borges-Andrade e Pagotto (2010).

A presente revisão está apoiada em dados quantitativos e qualitativos. Os quantitativos caracterizam os artigos analisados a partir das frequências das características metodológicas encontradas. Os qualitativos descrevem, a partir da análise do conteúdo dos estudos, as contribuições, os limites e os problemas enfrentados, visando a desvendar as forças e fraquezas teóricas e metodológicas desses relatos de pesquisas.

\section{Resultados}

Os resultados obtidos encontram-se estruturados em três segmentos: o primeiro apresenta os dados gerais que caracterizam a produção científica, com destaque para os aspectos metodológicos das pesquisas realizadas, o segundo descreve a rede de instituições e de pesquisadores envolvida nessa produção científica, e o terceiro apresenta uma análise de cada um dos temas, destacando suas contribuições para a área.

Com relação ao primeiro segmento, um primeiro e importante resultado a ser destacado refere-se ao número geral de trabalhos encontrados em periódicos brasileiros: 63 em 10 anos. Trata-se de um indicador da dimensão relativamente pequena da comunidade científica brasileira que se dedica ao tema, apesar de expressivo no conjunto de temas em Comportamento Organizacional no país. Um segundo aspecto importante refere-se à primazia que o interesse pelo estudo do comprometimento, em diversos focos, desperta no país (praticamente 50\% dos artigos). A Figura 2 mostra a distribuição dos artigos por ano e por categoria no período investigado.

É maior a frequência e estabilidade das pesquisas sobre comprometimento no trabalho ao longo dos anos. Estudos específicos sobre contratos psicológicos tiveram uma maior expressão no Brasil em 2010. As pesquisas sobre cidadania organizacional e sobre percepção de suporte e de justiça e equidade, ao contrário, foram mais expressivas na primeira metade da década. Curiosamente, essa tendência é observada no conjunto geral de publicações sobre vínculos no trabalho: a primeira metade da década, de 2001 a 2005, concentrou

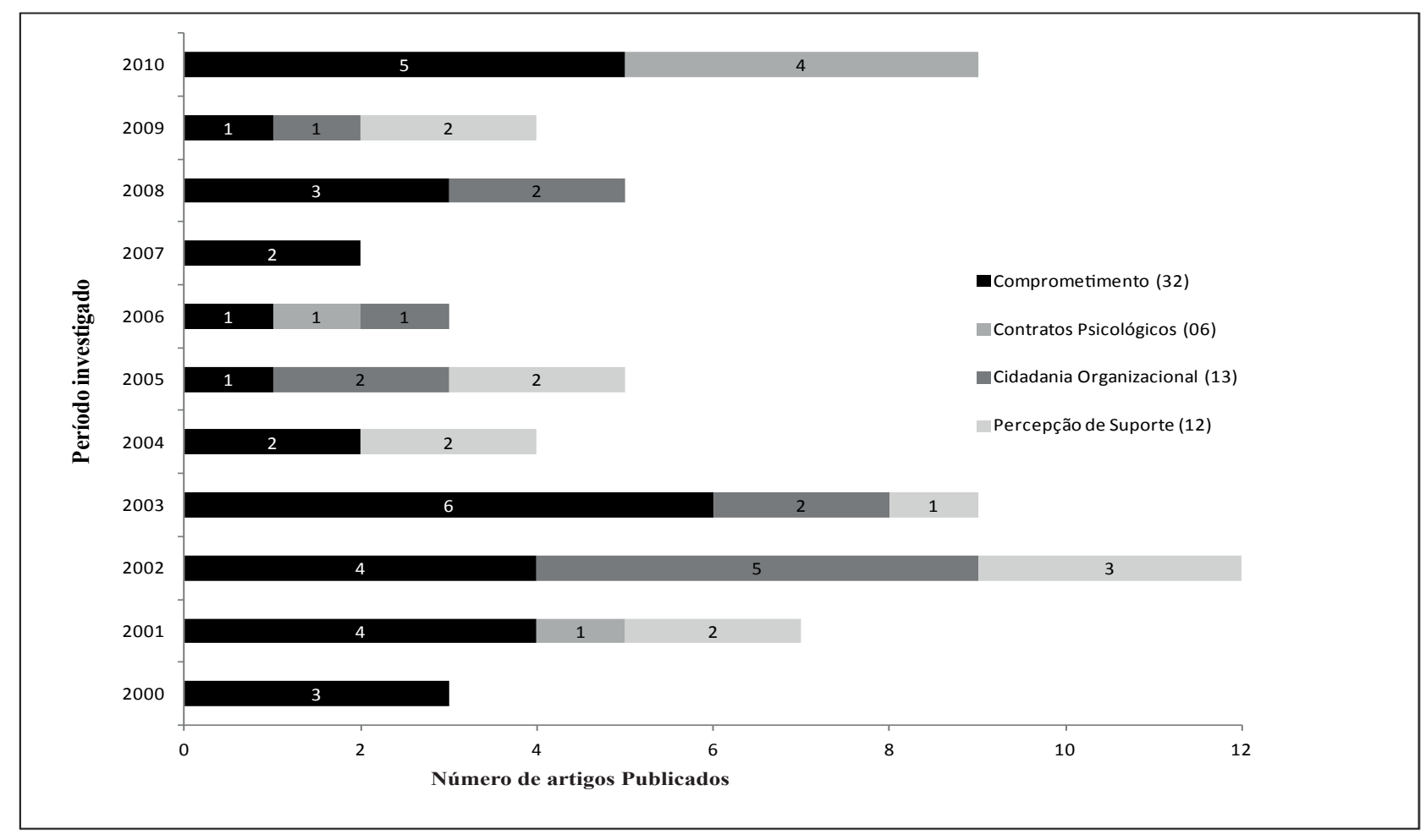

Figura 2. Artigos sobre vínculos no trabalho publicados nos periódicos brasileiros investigados 
$62 \%$ das publicações, enquanto que os anos subsequentes reuniram os $38 \%$ restantes dos estudos encontrados.

A Figura 3 resume as principais características metodológicas dos estudos analisados. A pesquisa sobre vínculos no trabalho prioriza delineamentos de investigação, em comparação aos relatos de experiência, seguindo a tendência de amadurecimento da área de Comportamento Organizacional. Os estudos teóricos são em menor número, indicando uma menor frequência de sistematizações e reflexões importantes para o desenvolvimento conceitual dos construtos investigados. O objetivo de gerar conhecimento é também preponderante, não havendo, entre as pesquisas sobre vínculos, a preocupação em produzir tecnologia. Os instrumentos gerados são, essencialmente, medidas a serem utilizadas em novos estudos da área. Isso é esperado de uma produção científica que ocorre na sua totalidade no ambiente acadêmico e no âmbito de grupos de pesquisa vinculados a programas de pós-graduação. A ausência da produção de técnicas ou a falta de uma preocupação clara com a transferência de conhecimentos para setores produtivos pode dificultar a aplicação, no contexto organizacional e do trabalho, dos conhecimentos produzidos.

Apesar do equilíbrio observado entre as abordagens quantitativas e qualitativas nas pesquisas brasileiras (BorgesAndrade \& Pagotto, 2010), nos estudos sobre vínculos no trabalho destacam-se claramente as primeiras. Em especial, a pesquisa sobre comprometimento no trabalho é fortemente impregnada pela quantificação, apresentando somente um estudo exclusivamente qualitativo e três que combinam ou confrontam perspectivas quantitativa e qualitativa. Como consequência dessa escolha metodológica mais geral, prevalece o uso de questionários e escalas como instrumentos de coleta de dados. São poucas as pesquisas que acrescentam instrumentos como entrevistas ou análises documentais. Os dados quantitativos favorecem o uso de análises inferenciais, quer exclusivamente, quer como recursos complementares a outras análises de caráter mais descritivo. Condizente com a presença predominante de surveys e estudos extensivos, as pesquisas sobre vínculos tendem a agregar amostras de diversas organizações, originadas principalmente dos setores público e privado da economia. O terceiro setor recebeu atenção de apenas dois estudos do total de 63 avaliados.

$\mathrm{O}$ segundo segmento que estrutura os resultados aqui obtidos descreve as redes de produção científica na área. A partir dos dados de autoria e vinculação institucional, utilizou-se a ferramenta de análise de redes sociais para mapear essas interações. O mapeamento dessas redes fornece importante informação sobre os arranjos que configuram o campo e podem ajudar a compreender características da produção científica identificada. Pode-se, por exemplo, perceber o porte dos seus grupos de pesquisa que mais publicaram no período. Há uma concentração de laços direcionados para duas instituições: UnB e UFBA. São os dois núcleos que se destacam pela maior participação no conjunto de produção científica examinada neste trabalho. A Universidade Federal de Lavras está relacionada com seis autores. A USP e Universidade do Minho-Portugal (aqui incluída, pois os artigos envolvem autores brasileiros em
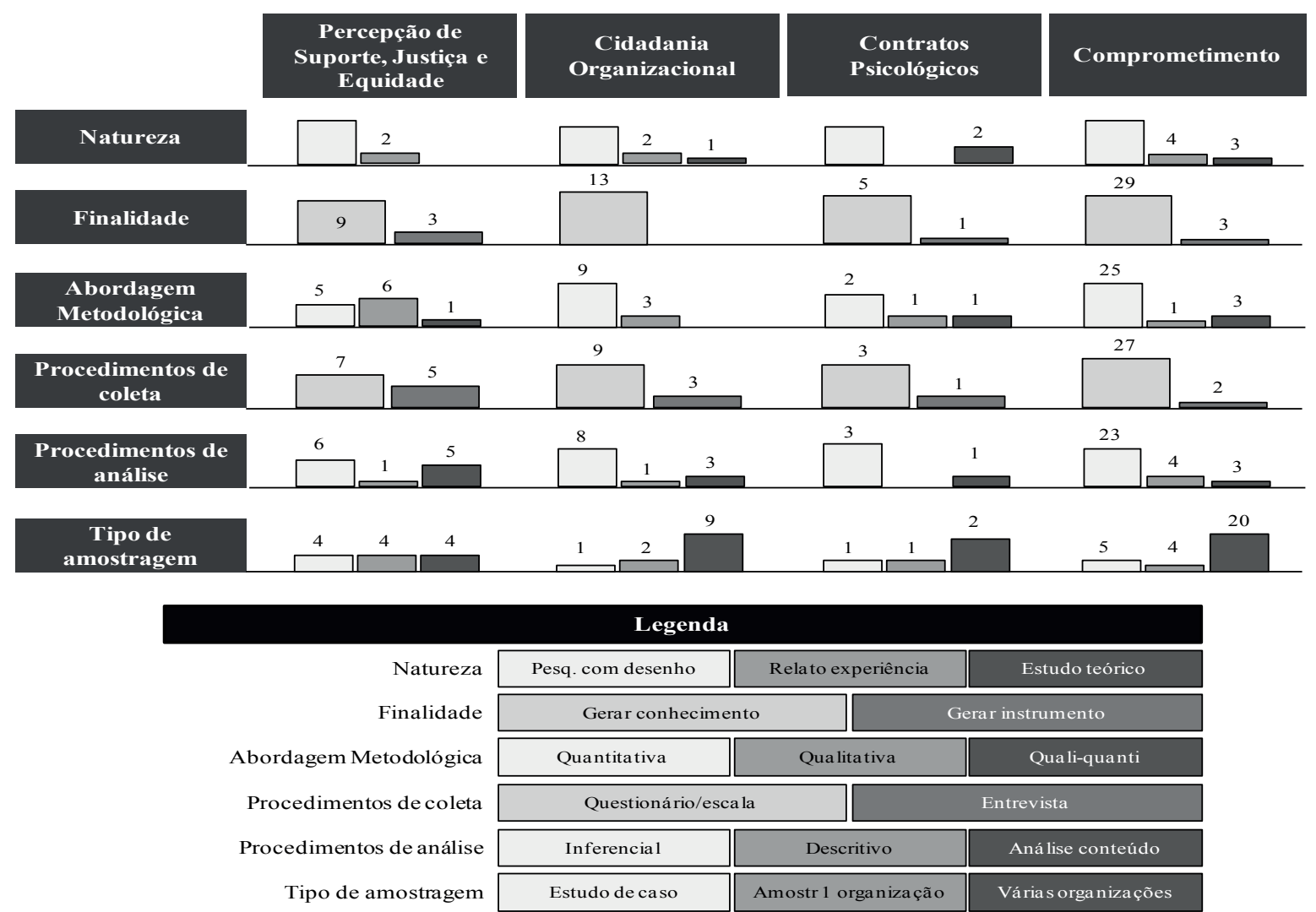

Figura 3. Características metodológicas dos estudos sobre vínculos na organização publicados nos periódicos brasileiros investigados. 
parceria com portugueses e foram publicados no Brasil, com base em dados deste país) apresentam, cada uma, quatro autores vinculados, sendo seguidas por outras instituições que apresentam três a dois autores.

Para obter uma informação mais ampla sobre a relação entre as instituições foi construída uma rede de atributos para essa análise, conforme mostrado na Figura 4. Cada símbolo, nesta Figura, representa uma instituição diferente, possibilitando visualizar as relações de coautoria entre instituições. A matriz de adjacências apresenta uma composição fragmentada com seis componentes, onde somente um se destaca e representa uma suposta aliança, exatamente entre os dois núcleos com maior participação. Como resultado, há uma rede que domina mais da metade da produção científica, sugerindo uma grande desproporcionalidade, quando comparado o seu tamanho com o tamanho das outras cinco redes.

Os resultados obtidos sugerem que, apesar de haver relações entre autores de diferentes instituições, a densidade das relações internas ainda supera a densidade das relações externas na relação de autoria e coautoria. Esse resultado seria esperado, pois os autores naturalmente buscam relações de coautoria com colegas da mesma instituição pela facilidade da aproximação geográfica. Mas, por outro lado, pode gerar uma homogeneidade nos trabalhos, reduzindo a ampliação das discussões entre diferentes perspectivas e possibilidades de interpretações e análises nos seus temas de estudo.

O terceiro segmento de estruturação dos resultados apresenta e discute as tendências e desafios de pesquisa para o tema. A pesquisa sobre o comprometimento no trabalho aponta para quatro principais blocos de investigação, que refletem o grau de complexidade alcançado pelos estudos publicados no Brasil e, especialmente, fora do país nas últimas décadas. $\mathrm{O}$ primeiro bloco consolida a tradição de estudos de antecedentes e consequentes do comprometimento (Bastos, 1994; Meyer et al., 2002) e segundo, também tradicional e igualmente relevante, volta-se para os seus focos (Bastos \& Borges-Andrade, 2002; Fink, 1992). O terceiro bloco detém-se na discussão das questões conceituais e empíricas do vínculo (Rodrigues \& Bastos, 2010; Solinger, Van Olffen, \& Roe, 2008), e o quarto compõe reflexões sobre a gestão do comprometimento nas organizações de trabalho (Bastos, Rodrigues, Moscon, Silva, \& Pinho, no prelo; Wright \& Kehoe, 2009). Esse último bloco, embora esteja circunscrito às análises de antecedentes e consequentes, apresenta lacunas ligadas aos impactos e à efetividade das práticas organizacionais e de gestão de pessoas nos níveis de comprometimento dos empregados.

Tamanha complexidade caracteriza o comprometimento no trabalho como o construto mais representativo na tradição de pesquisa sobre vínculos no Brasil. Por esse motivo, sua agenda de pesquisa é também a que apresenta maiores avanços nas verificações empíricas e maior atenção aos problemas que ameaçam a validade dos seus resultados. Ainda assim, a análise da produção dos últimos 11 anos (2000 a 2010) indica lacunas e tendências de crescimento e extinção, que demandam novos direcionamentos para a pesquisa.

Com relação aos estudos sobre focos do comprometimento, nota-se uma diminuição de investigações específicas sobre padrões de vínculo, que analisem as combinações do

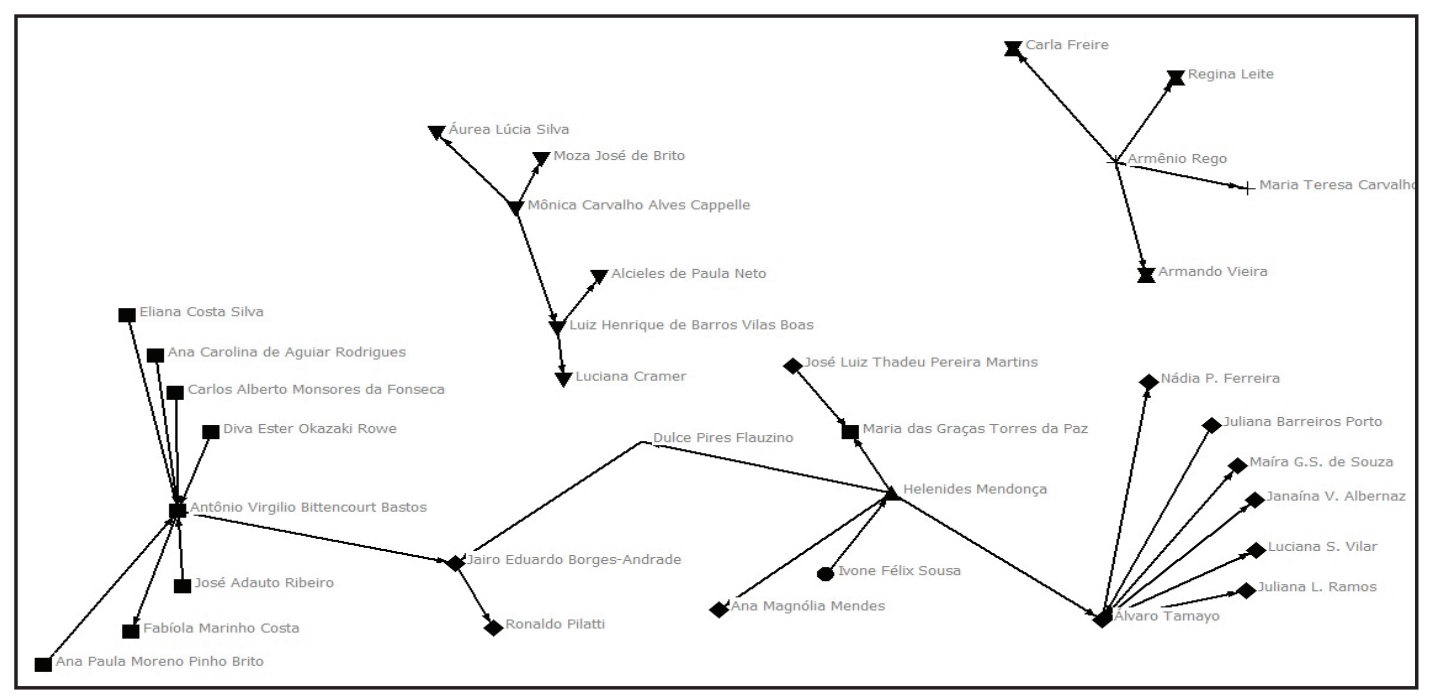

\begin{tabular}{|c|c|c|c|c|c|c|}
\hline \multicolumn{7}{|c|}{ Legenda } \\
\hline Nome da Instituição & $\begin{array}{l}\text { Universidade de } \\
\text { Aveiro-Portugal }\end{array}$ & $\begin{array}{c}\text { Universidade de } \\
\text { Brasília }\end{array}$ & $\begin{array}{l}\text { Universidade do } \\
\text { Minho-Portugal }\end{array}$ & $\begin{array}{c}\text { Universidade } \\
\text { Federal da Bahia }\end{array}$ & $\begin{array}{c}\text { Universidade } \\
\text { Federal de Lavras }\end{array}$ & $\begin{array}{c}\text { Pontifícia } \\
\text { Universidade } \\
\text { Católica de Goiás }\end{array}$ \\
\hline $\begin{array}{c}\text { Número de } \\
\text { Representantes }\end{array}$ & 02 & 11 & 03 & 08 & 06 & 01 \\
\hline Símbolo na matriz & Símbolo de Soma & Diamante & $\begin{array}{l}\text { Triângulos } \\
\text { invertidos } \\
\text { sobrepostos }\end{array}$ & Quadrado & Triangulo Invertido & Círculo \\
\hline
\end{tabular}

Figura 4. Rede de produção de artigos científicos com mais de uma relação de coautoria por instituição. 
comprometimento com diferentes focos (organização, ocupação, sindicato e carreira). Essa lacuna prejudica a compreensão de como os vínculos com diferentes focos se inter-relacionam, desconsiderando ainda o impacto de múltiplos vínculos no desenvolvimento do comprometimento no trabalho.

A maior parte das publicações (75\%) volta-se para a investigação de antecedentes e consequentes, com uma clara prioridade de estudo de antecedentes. Desses, o mais proeminente é o estudo da percepção de justiça e equidade, que manteve estabilidade em sua participação como objeto de investigação ao longo dos anos. Essa constância devese ao papel desempenhado por um grupo de pesquisa, que manteve uma agenda voltada para avaliação das relações entre percepção de justiça e equidade e comprometimento organizacional, com muitos estudos comparativos entre trabalhadores brasileiros e portugueses.

Nota-se, ainda, a preocupação com um conjunto de variáveis categorizadas como organizacionais e referentes à gestão, a exemplo de estrutura, missão, filosofia e valores organizacionais, características organizacionais autentizóticas, sistemas de RH e gestão de pessoas. Portanto, os pesquisadores reconhecem e identificam o papel do contexto na formação e desenvolvimento do comprometimento, especialmente com foco na organização. Embora muitas pesquisas (41\%) relatem também a investigação de variáveis pessoais e funcionais, sua utilização tem sido mais comum para a caracterização das amostras ou diferenciação dos grupos do que para a avaliação de seus impactos no comprometimento no trabalho. Somente três estudos nos últimos 11 anos estiveram voltados para a investigação de consequentes do comprometimento com a organização e com a carreira, no caso, o desempenho. O principal risco dessa lacuna é que, na falta de verificações empíricas, pesquisadores e até gestores pautem hipóteses, interpretações ou ações gerenciais em resultados encontrados fora do nosso contexto. Nessas publicações brasileiras sobre antecedentes e consequentes, é notável a transição paulatina do uso de medidas unidimensionais para medidas multidimensionais do comprometimento organizacional.

O Organizational Commitment Questionnaire (OCQ), construído por Mowday et al., (1982), e que teve sua versão brasileira ajustada por Bastos (1994), foi utilizado de forma mais concentrada nos estudos do primeiro triênio investigado, com uma única exceção (Flauzino \& Borges-Andrade, 2008). Nos anos seguintes, esse questionário foi utilizado em apenas quatro trabalhos, sendo sua utilização substituída por medidas multidimensionais, fortemente influenciadas pela escala do modelo tridimensional de Meyer e Allen (1991). Esse questionário serviu ainda de inspiração para a construção e validação de outras medidas, talvez como uma busca de alternativa para problemas de consistência interna encontrados nas aplicações da versão brasileira do mesmo. Além do OCQ e da escala de Meyer e Allen (1991), alguns estudos utilizaram medidas com novos arranjos, constituídas por subdimensões das três bases propostas por Meyer e Allen. Essa indefinição das medidas de comprometimento organizacional empregadas é agravada ainda mais pelas baixas consistências internas encontradas em alguns casos, o que afeta a validade e confiabilidade dos resultados.
Para resolver alguns desses problemas, começam a ser desenvolvidos estudos sobre conceitos e medidas de outros vínculos, como entrincheiramento e consentimento organizacional (Magalhães, 2008; Rodrigues \& Bastos, 2012; Silva \& Bastos, 2010). Esses estudos foram incluídos nesta revisão por serem originados da agenda de pesquisa sobre comprometimento no trabalho e por serem objeto das investigações que estão reunindo evidências da delimitação dos vínculos. A existência desses estudos pode ser considerada um dos indicadores de amadurecimento da área. Diante de todas as questões conceituais e empíricas discutidas e sistematizadas por Rodrigues e Bastos (2010), as investigações sobre esses novos vínculos propõemse a contribuir para uma maior precisão do construto de comprometimento no trabalho, como ponto de partida para uma melhor operacionalização e, assim, maior validade dos achados científicos.

Expõem-se como diretrizes para a pesquisa sobre comprometimento no trabalho: 1) intensificação dos estudos que possibilitem uma maior demarcação das suas fronteiras conceituais, por investigações de validade discriminante em relação a outros construtos e que explorem qualitativamente os conceitos empregados; 2) maior cautela em relação às medidas utilizadas, cujas propriedades psicométricas devem ser continuamente avaliadas e descritas em cada estudo, como forma de monitorar seus impactos na validade dos resultados; 3 ) ampliação da investigação de antecedentes e consequentes, com atenção para suprir também a lacuna de estudos sobre gestão dos múltiplos comprometimentos nas organizações de trabalho; 4) atenção às relações existentes entre vínculos ligados a diferentes focos, de modo a evitar pesquisas que isolem e privilegiem o foco organizacional; e 5) realização de estudos com delineamentos qualitativos, não somente voltados para a análise de conteúdo das percepções dos atores organizacionais, mas também preocupados com a compreensão da formação e dinâmica do comprometimento no trabalho.

A incipiência da pesquisa sobre contrato psicológico no período analisado pode ser demonstrada pelos resultados obtidos por meio deste estudo: os 14 periódicos nacionais pesquisados no período de 2000 a 2010 exibem apenas quatro trabalhos de cunho empírico e dois ensaios teóricos sobre o tema. Os estudos sobre esse construto no Brasil e fora do país são marcados pela grande influência da definição de contrato psicológico como "crenças relativas aos termos e às condições de um acordo de trocas recíprocas entre um indivíduo e um grupo" (Rousseau, 1995, p. 19). Menegon e Casado (2006) questionam essa definição, construída sob o termo crença, por se tratar o contrato psicológico, antes de tudo, de um processo de negociação e acordo entre as partes. Essas autoras adotam a definição de contrato psicológico como um "conjunto de expectativas individuais recíprocas relativas às obrigações (o que o empregado 'deve') e aos direitos (o que o empregador 'deve')" (Kidder \& Buchholtz, 2002, p. 562). Verifica-se um crescente interesse pelo tema no Brasil, haja vista a concentração de artigos encontrados nos últimos cinco anos.

A preponderância de métodos qualitativos e exploratórios na pesquisa da área aponta a necessidade de que esta avance complementando-se com os métodos quantitativos. Uma 
lacuna essencial, que pode estar impedindo esses avanços, é representada pela falta de instrumento validado para a realidade brasileira. Essa validação implica, sobretudo, em verificar se as dimensões definidoras do construto na pesquisa internacional aparecem ou não na realidade brasileira. De estudos como este é que pode vir a consolidarse um conceito mais geral de "contrato psicológico" que se aplique a diferentes contextos culturais. Nesse sentido, é importante destacar a contribuição de Santos e Gonçalves (2010) para áreas consideradas centrais no estudo de contrato psicológico, de violação e quebra, com a adaptação de duas escalas relativas ao incumprimento do contrato psicológico à língua portuguesa. Sugere-se a realização de mais estudos com amostras mais heterogêneas e de maneira complementar a outros métodos. O corte transversal da pesquisa, opção metodológica de todos os artigos analisados é insuficiente para capturar a dinâmica do contrato psicológico. A investigação por meio de estudos longitudinais torna-se uma necessidade premente, para que se inicie a produção de conhecimento do contrato psicológico como variável preditora de outras variáveis, como motivação, comprometimento no trabalho, desempenho, cidadania organizacional, rotatividade e retaliação, por exemplo. Como ressaltam Correia e Mainardes (2010, p. 276), "falta ainda um modelo abrangente e integrado (...) o que existe é um conjunto muito vasto de estudos, que apontam para a influência desta ou daquela dimensão do contrato psicológico no desempenho individual e global da organização". Outra limitação que não se restringe ao contexto brasileiro, constituindo uma limitação aos estudos internacionais também, é a falta de estudos que partam da perspectiva do empregador para análise do conteúdo do contrato psicológico.

Apesar de não se tratar de um tema de pesquisa incipiente no Brasil, como ocorre com contratos psicológicos, a pesquisa sobre cidadania organizacional também não é muito representativa. Ocorreu a publicação de 14 trabalhos de cunho empírico nos 14 periódicos nacionais revisados no período de 2000 a 2010. Contudo, diferentemente do que ocorre no cenário de pesquisa fora do país, o interesse pelo tema é decrescente: a produção dos últimos cinco anos equivale a menos de $30 \%$ de todo o período analisado. Da análise desses artigos depreende-se que cada um adota um instrumento de medida de cidadania organizacional diferente e alguns possuem consistências internas inferiores ao desejável. Mesmo em relação ao mais consistente dentre os instrumentos adotados, seria recomendável a aplicação a um número maior de respondentes e de organizações para viabilizar a generalização dos resultados. Seria ainda desejável indicar um caminho para a consolidação de um instrumento que sirva como referência para estudos brasileiros.

A adoção de delineamentos de pesquisa que permitissem análises estatísticas mais sofisticadas seria recomendável para extração de nexos de causalidade entre as variáveis. O levantamento de percepções de terceiros acrescentaria mais informações para investigar um fenômeno susceptível de desejabilidade social, como é o caso da cidadania organizacional. Mesmo sem clareza sobre bons indicadores de cidadania organizacional, a pesquisa sobre o tema tem se voltado para o estudo de seus antecedentes e consequentes.
Quase metade dos artigos têm como foco esses antecedentes, provavelmente por conta do seu potencial pragmático para intervenções. Essa imaturidade conceitual, após mais de 20 anos, reflete-se na sobreposição conceitual entre cidadania e comprometimento organizacionais ou no descuido na diferenciação entre os comportamentos de cidadania e extrapapel, ou no uso de conceitos similares como comportamentos pró-sociais e espontaneidade organizacional. A não existência de consenso entre os pesquisadores com relação a conceitos, sua operacionalização e sua dimensionalidade aponta a lacuna mais importante: a necessidade de embasamento teórico mais sólido para o construto. $\mathrm{O}$ avanço da pesquisa na área depende essencialmente da integração da literatura, do amadurecimento de um conceito bem delimitado e consensual e de formas de operacionalização sistematicamente aplicadas e bem aceitas no meio.

As percepções de suporte organizacional e de justiça e equidade constituíram o objeto de pesquisa para 17 artigos encontrados no período de 2000 a 2010. Esses artigos adotaram predominantemente métodos quantitativos e abarcaram os setores público e privado da economia. Foram desenvolvidos instrumentos de medida para justiça e equidade e discutida a dimensionalidade do construto. No período analisado, percepção de justiça e equidade foi investigada como antecedente de comprometimento organizacional em quatro artigos, assim como o suporte organizacional. $\mathrm{O}$ interesse por percepções de suporte organizacional e de justiça e equidade parece ter diminuído na segunda metade da década. Apenas dois estudos foram publicados depois de 2005. O tema de comportamentos disfuncionais, em particular, que emerge em contrapartida às pesquisas sobre cidadania organizacional, surgiu recentemente no Brasil. Contudo, não teve forças para continuar se desenvolvendo. Esse tema é incipiente e carente de novos estudos e mereceria mais atenção. Seria desejável uma maior articulação entre as percepções de suporte e de justiça organizacional e retaliação nesses estudos.

\section{Considerações Finais}

O exame da produção científica de um determinado campo, independente da sua abrangência ou amplitude, é uma importante tarefa para a comunidade científica. A própria produção da ciência torna-se, cada vez mais, objeto da investigação científica. A maior expectativa de estudos dessa natureza consiste na geração de insights sobre os limites, as lacunas e as dificuldades encontradas pelos pesquisadores e, evidentemente, o reconhecimento dos avanços conseguidos. Desses insights, pode surgir uma nova agenda de pesquisa para o campo, algo fundamental para a ciência, um empreendimento de natureza histórica e coletiva. Além daquela produção, também o processo que levou a ela pode ser examinado, exatamente no que tange a essa natureza histórica e coletiva.

O presente trabalho fez um recorte bastante específico do seu objeto de análise - os estudos sobre os vínculos do trabalhador na organização. A análise realizada teve o foco na produção mencionada, mas também levou em conta a natureza histórica e coletiva do empreendimento, ao 
acompanhar essa produção ano a ano e identificar as redes sociais dos seus produtores. Há uma efetiva limitação em termos de número de pesquisadores dedicados ao estudo dos vínculos dos indivíduos nas organizações, o que explica o volume relativamente incipiente da produção científica brasileira. A análise de redes deixa isso bastante claro e revela a pouca articulação ou os frágeis laços dos pesquisadores, pelo menos para gerarem produtos como artigos. $\mathrm{O}$ tamanho da comunidade leva a que a produção não tenha uma grande estabilidade e que não se perceba uma clara tendência, ao longo do tempo, com uma flutuação acentuada da quantidade de itens publicados.

No Brasil, duas instituições participam de uma rede que ocupa mais da metade de todo esse empreendimento produtivo, fora das regiões sul e sudeste, que detêm o maior desenvolvimento econômico, onde está localizada a maioria das instituições de ensino e a maioria das organizações do setor produtivo. Esses dois núcleos que se destacam como mais voltados para o domínio são a UnB e a UFBA. De alguma forma, mesmo que não concretizada em termos de artigos produzidos no período 2000-2010, esses dois núcleos mantêm laços com outros núcleos tais como as Universidades Federais de Uberlândia, de Minas Gerais e do Rio Grande do Norte, a Empresa Brasileira de Pesquisa Agropecuária e o Serviço Federal de Processamento de Dados. O aprofundamento de laços entre esses núcleos para o desenvolvimento de projetos de maior escopo pode se constituir em um item importante da agenda futura da área. Permitirá, via esforço coletivo, realizar estudos que possam enfrentar os dilemas conceituais e os desafios empíricos que estão postos.

O padrão da pesquisa realizada no Brasil, em termos quantitativos, segue o quadro de pesquisa que se observa fora do país. Comprometimento organizacional é o vínculo mais intensamente estudado e pode ser considerado aquele com maior tradição de estudo e o mais representativo para o campo. É o construto em que a pesquisa mais avançou na compreensão dos seus antecedentes, correlatos e consequentes. Os outros construtos receberam atenção diferenciada mais recentemente, portanto, ainda se encontram em estágios menos avançados em termos de desenvolvimento científico. No perfil metodológico das pesquisas brasileiras predominam os surveys, com coleta de dados por meio de instrumentos padronizados e validados (frequentemente escalas de atitudes), o que permite análises estatísticas descritivas e inferenciais. Há um pequeno contingente de estudos qualitativos ou que combinam as duas abordagens. Os estudos geralmente utilizam decisões metodológicas corretas e adequadas a esse tipo de delineamento de pesquisa. Os problemas mais comuns referem-se ao uso de amostras de conveniência, estudos limitados a um único contexto organizacional e o pouco investimento em modelos estatísticos mais sofisticados para análise dos dados. Só recentemente surgiram estudos usando modelagem de equações estruturais para validar instrumentos e testar modelos explicativos, sobretudo em comprometimento no trabalho.

O exame de cada micro-vertente de pesquisa, sobre cada um dos quatro vínculos analisados, mostra situações diferenciadas no tocante ao amadurecimento da pesquisa realizada no Brasil. Há clara distinção dos estudos sobre comprometimento no trabalho em relação aos demais. No caso dos contratos psicológicos, os poucos estudos realizados ainda impõem uma agenda de pesquisa mais árdua que envolve a própria definição do construto e a adequação de instrumento para a sua avaliação. A pesquisa sobre percepções de suporte e de justiça e equidade revela que estas entram mais como um componente importante para explicar outros fenômenos do que um objeto de interesse em si mesmo. Finalmente, o construto de cidadania organizacional não apresentou um crescimento de estudos no cenário brasileiro. Apresentou inúmeras dificuldades conceituais e metodológicas relativas à sua mensuração. Apesar de serem feitas menções a comportamentos, as medidas são sempre atitudinais ou baseadas em relatos dos próprios trabalhadores. Um importante item de uma agenda para esse domínio de pesquisa deve envolver os limites conceituais e empíricos entre os construtos relativos aos vínculos na organização.

Os problemas de limites pouco precisos, de definições que se confundem e de instrumentos com claras sobreposições de itens são bem mais fortes quando se trata de comprometimento e cidadania. Esses dois construtos, surgidos no contexto internacional, permanecem diferenciados. Entretanto, existem fortes evidências de que os comportamentos de cidadania organizacional se confundem com os indicadores comportamentais de comprometimento, no caso do foco com a organização. Há fragmentação, confusão conceitual, extensões injustificadas de conceitos que, no seu conjunto, dificultam a articulação dos dados já disponibilizados pela pesquisa sobre os vínculos do trabalhador com a organização. Por extensão, impedem a construção de modelos teóricos mais abrangentes e confiáveis. Esses modelos são quase sempre parciais e limitados, porque muitos estudos são conduzidos em amostras por conveniência, sem representatividade de segmentos mais amplos de trabalhadores e de organizações. Há ainda a dificuldade de integrar, em estudos quantitativos, a ampla gama de fatores, de diferentes níveis, que afetam a natureza e a intensidade dos vínculos na organização.

O campo de estudo sobre comprometimento no trabalho, o que mais avançou, ainda apresenta sérios problemas conceituais. Esforços estão sendo realizados, no sentido de ampliar a precisão conceitual e de mensuração desse vínculo. Novos tipos de vínculos estão sendo estudados (entrincheiramento e consentimento), para diferenciá-los do comprometimento no trabalho e "limpar" esse construto. Há um imenso caminho a ser percorrido, sobretudo para fazer com que os desenvolvimentos conseguidos no cenário brasileiro tenham impacto na produção científica internacional. As pesquisas revisadas oferecem importantes insumos para a compreensão da realidade brasileira sobre as relações entre o trabalhador e sua organização. Não há uma clara e sistemática vinculação da pesquisa acadêmica com as realidades organizacionais. Contudo, o fato de serem pesquisas de campo, conduzidas em diferentes contextos de trabalho, assegura algum potencial de contribuir para o aprimoramento das políticas e práticas voltadas para a gestão. O conjunto de artigos analisados oferece, em comum, uma visão de que as relações do trabalhador na organização precisam ser mais justas e equilibradas. Devem ser relações de "mão de via dupla", se as organizações desejam que os 
vínculos se traduzam em desempenhos contributivos para a qualidade do seu desempenho e cumprimento da sua missão social. Afinal, a riqueza e complexidade de tais vínculos é um dos pilares que sustentam a noção de que organizações são muito mais do que a simples soma de pessoas que nelas trabalham.

\section{Referências}

Argyris, C. (1960). Understanding organizational behaviour. Homewood, Illinois: Dorsey Press.

Bastos, A. V. B., \& Borges-Andrade, J. E. (2002) Comprometimento com o trabalho: padrões em diferentes contextos organizacionais. Revista de Administração de Empresas, 42(2), 1-11. doi: 10.1590/S0034-75902002000200003.

Bastos, A. V. B. (1994). Comprometimento no Trabalho: a estrutura dos vínculos do trabalhador com a organização, a carreira e o sindicato. [Unpublished doctoral dissertation]. Universidade de Brasília, Brasília.

Bastos, A. V. B., Rodrigues, A. C. A., Moscon, D. C. B., Silva, E. E. C., \& Pinho, A. P. M. (2013). Comprometimento no trabalho: fundamentos para a gestão de pessoas. In L. O. Borges \& L. Mourão (Eds.), As pessoas, o trabalho e as organizações: intervenções a partir da Psicologia. Porto Alegre: Artmed.

Borges-Andrade, J. E., \& Pagotto, C. do P. (2010). O estado da arte da pesquisa brasileira em Psicologia do Trabalho e Organizacional. Psicologia: Teoria e Pesquisa, 26, 37-50. doi: 10.1590/S0102-37722010000500004.

Brown, R. (1996). Organizational commitment: Clarifying the concept and simplifying the existing construct typology. Journal of Vocational Behavior, 49(3), 230-251.

Cooper-Hakim, A., \& Viswesvaran, C. (2005). The construct of work commitment: Testing an integrative framework. Psychological Bulletin, 131(2), 241-259.

Correia, R., \& Mainardes, E. W. (2010). O desenvolvimento do contrato psicológico orientado para desempenhos de elevado rendimento. Psico (PUCRS), 41(2), 266-277.

Eisenberger, R., Huntington, R., Hutchison, S., \& Sowa, D. (1986). Perceived organizational support. Journal of Applied Psychology, 71(3), 500-507.

Fink, S. L. (1992). High commitment workplaces. New York: Quorum Books.

Flauzino, D., \& Borges-Andrade, J. (2008). Comprometimento de servidores públicos e alcance de missões organizacionais. Revista de Administração Pública, 42(2), 253-273.

Gouldner, A. (1960). The norm of reciprocity: a preliminary statement. American Sociological Review, 25(2), 161-178.

Kidder, D. L., \& Buchholtz, A. K. (2002). Can excess bring success? CEO compensation and the psychological contracts. Human Resources Management Review, 12(4), p.599-617.

Levinson, H., Price, C. R., Munden, K. J., \& Solley, C. M. (1962). Men, management, and mental health. Cambridge, MA: Harvard University Press.

Magalhães, M. O. (2008). Propriedades psicométricas da versão brasileira da Escala de Entrincheiramento na Carreira. PsicoUSF, 13(1), 13-19.

Menegon, L. F., \& Casado, T. (2006). O contrato psicológico como ferramenta para a gestão de pessoas. Revista de Administração (FEA-USP), 41(2), 125-135.
Menninger, K. (1958). Theory of psychoanalytic technique. New York: Basic Books.

Meyer, J., \& Allen, N. (1991). A three-component conceptualization of organizational commitment. Human Resource Management Review, 1(1), 61-89.

Meyer, J., Stanley, D., Herscovitch, L., \& Topolnytsky, L. (2002). Affective, continuance, and normative commitment to the organization: A meta-analysis of antecedents, correlates, and consequences. Journal of Vocational Behavior, 61(1), 20-52.

Morrow, P. (1983). Concept redundancy in organizational research: The case of work commitment. Academy of Management Review, 8(3), 486-500.

Mowday, R. T., Porter, L. W., \& Steers, R. M. (1982). Employeeorganization linkages: The psychology of commitment, absenteeism, and turnover. New York: Academic Press.

Organ, D. W. (1988). Organizational citizenship behavior: The good soldier syndrome. Lexington, MA: Lexington Books.

Osigweh, C. B. (1989). Concept, fallibility in Organizational Science. Academy of Management Review, 14(4), 579-594.

Rhoades, L., \& Eisenberger, R. (2002). Perceived organizational support: A review of the literature. Journal of Applied Psychology, 87(4), 698-714.

Rodrigues, A. C. A., \& Bastos, A. V. B. (2010). Problemas conceituais e empíricos na pesquisa sobre comprometimento organizacional: uma análise crítica do modelo tridimensional de J. Meyer e N. Allen. Revista Psicologia - Organizações e Trabalho, 10(2), 129-144.

Rodrigues, A. C. A., \& Bastos, A. V. B. (2012). Entrincheiramento organizacional: construção e validação da escala. Psicologia: Reflexão e Crítica, 25(4), 688-700.

Rousseau, D. (1989). Psychological and implied contracts in organizations. Employee Responsibilities and Rights Journal, 2(2), 121-139.

Rousseau, D. M. (1995). Psychological contracts in organizations: Understanding written and unwritten agreements. Thousand Oaks, CA: Sage.

Santos, J. D., \& Gonçalves, G. (2010). O incumprimento do contrato psicológico: contributo para a adaptação de escalas de violação e ruptura. PSICO, 41, 259-265.

Schein, E. H. (1965) Organizational Psychology. Englewood Cliffs, NJ: Prentice-Hall.

Silva, E. E. C., \& Bastos, A. V. B. (2010) A escala de consentimento organizacional: construção e evidências de sua validade. Revista Psicologia - Organizações e Trabalho, 10(1), 7-22.

Solinger, O., Van Olffen, W., \& Roe, R. (2008). Beyond the threecomponent model of organizational commitment. Journal of Applied Psychology, 93(1), 70-83.

Wright, P. M., \& Kehoe, R. R. (2009). Organizational-level antecedents and consequences of commitment. In H. J. Klein, T. E. Becker, \& J. P. Meyer (Eds.), Commitment in Organizations: Accumulated wisdom and new directions (pp. 285-307). New York: Routledge/Taylor and Francis Group.

Recebido em 21.11.2012

Primeira decisão editorial em 21.01.2013

Versão final em 11.04.2013

Aceito em 21.05.2013 